\section{PHYSICISTS AFTER THE WAR*}

\author{
By SIR LAWRENCE BRAGG, O.B.E., F.R.S. \\ Cavendish Laboratory, Cambridge
}

$\mathrm{W}$ HILE scientific men of all kinds have been called upon to use their skill and knowledge for the nation's service in the present War, certain classes have been in especial demand, and the physicist is ranked among these 'scarcity categories'. The demand for physicists exceeds the supply, and universities have been pressed to train as many men as possible to fill the gap. There was no such general demand for the services of scientists in the War of 1914-18. Although there were some technical applications which called for trained scientific men, in the main that war was fought with comparatively simple gear. Physicists are now being used to develop and use all the lighter apparatus of war, the instruments for communication, for detection of aircraft and submarines, and for direction of our batteries. They are increasingly applying their analytical technique to operational research into the most effective way of using our weapons. Many of these latest developments are directed by men supplied by our industrial or university laboratories.

Physicists in general have been drawn into the service of the country in a way that has never happened before, and for the university scientist in particular this has meant a change of outlook and of occupation of a very revolutionary kind. In peacetime, the pure scientist, as contrasted with the applied scientist, works in a world of his own, not because he is an unpractical dreamer, as is often supposed, but for a very different reason. $\mathrm{He}$ is generally carrying out his particular task, the discovery of new knowledge, in an efficient and practical way, but although his researches may eventually have far-reaching consequences in altering the conditions of everyday life, he is cut off from these applications by a long interval of time. It is unusual for any great discovery in pure science to find an application in everyday use in less than thirty or forty years, since this time is required for the technical industrialist to see its possibilities and explore methods of using it for practical purposes. In the War, the pure scientist has to join the applied scientists and become a technician. He has to use his skill and knowledge to aid in devising gear which can be put to practical use in one or two years. A wider world has been opened up to men of science as the result of their being drawn into the War. They see more of the way the country is run. They are accused, with considerable justice, of being somewhat free in their criticism of many of the things they are seeing for the first time. Some of these criticisms are ill-founded, being due to a slowness in realizing that a country is a more complex entity to organize than a laboratory, but some are worth listening to, because they come from a body of men whose discoveries have been largely responsible for introducing the new technological era, which has completely altered the way we all live.

One thing has been clear. It has been of immense advantage to Great Britain in this struggle to have a reservoir of scientific researchers on which to draw. Their contributions cannot be described now, but when it is possible to do so, it will be found that our men of science have played no small part at more than one critical time. We are all hoping that we shall not drift back after the War, but will use our national

* From a lecture at the Royal Institution, delivered on March 26. assets of character and brains to make the country a better one than it has been during the last twenty years. I wish here to take stock of one particular part of these assets, our body of physicists, attempting to see what material we have got and make some suggestions as to how we could train and use it better.

My own experience has been gained in university work, and it is inevitable that this article should reflect the views thus engendered. I should be very sorry, however, if any part of it were taken to indicate a belief that the physicist who devotes himself to pure science has higher ideals or is more representative of his profession than his colleague who devotes his gifts to applied science. It is to our discredit as university men that we should sometimes be accused as a body of holding such views; it is evidence of a failure to take responsibility and enter into the life of the country. I hope, on the other hand, that it will be clear from what I have written that I am seeking to set our own house in order, to see how we can best equip the students committed to our care to take their part in applying their science for the benefit of all.

\section{A Census of Physicists}

It is interesting to assess the number of scientists, and of physicists in particular, in Great Britain. An estimate can be got in two different ways which roughly check each other. In the first place, we can find from the records of universities the rate at which scientists are being produced. The calculation is most straightforward in the case of the large modern universities. Each of these, such as Birming. ham, Manchester, Leeds, or Liverpool, is the centre of a drainage area separated by watersheds. The students on the whole join that university to which they can travel backwards and forwards daily from their homes, and so one can calculate with some exactitude how many millions of the population each serves. From my experience at Manchester and as external examiner in other universities, I arrived at a rough estimate that one good physicist was bred per year per million inhabitants. By a good physicist I mean a man capable of independent thought, with a flair for his subject. For example, at Manchester, where we had excellent secondary schools seeking out and training all likely material, three or four such men a year was the average product drawn from a population of about four millions.

Again, we now have for the first time a census of the men of science in Great Britain; it is provided by the Central Register initiated by the Royal Society. The card index of the Central Register contains the names of all scientists in Great Britain, together with information about their scientific careers, experience and special interests. The term 'scientist' is not easy to define, but it has been taken to cover all who have received higher scientific education, have taken up a post in industry, Government service or the universities, and have continued to use their scientific knowledge for research or administration. The total number of scientists on the list at the beginning of the War was 12,000, of whom 1,200 were physicists. We may compare this with the above estimate that the population of Great Britain of 45 millions is producing one physicist per million per year; if one takes an average working life of thirty years, the two estimates agree. It is of course true that the relative numbers of scientists in different categories might be changed by a change in the 
importance and interest of the various branches, but it is doubtful if the grand total could be much increased. The net cast by the system of scholarships is so effective that most school students who show intellectual promise have the opportunity of higher education. One curious exception is to be noted, the very small proportion of scientists coming from the great public schools. Whether this is due to the direction of the brightest boys at these schools into other subjects, or to the fact that boys from the well-to-do homes which can afford a public school education are naturally drawn into other walks of life, I do not venture to judge; but it is an interesting fact, for example, that among the heads of physical laboratories in Great Britain, only one in a hundred received his education as a boarder at a public school. The secondary schools and grammar schools are the source from which the body of British scientists is almost entirely drawn.

\section{Fundamental Research}

How can we best use the physicists which Great Britain breeds, both for pure research and for the equally vitally important industrial research? To take in the first place the well-head from which the flow of scientific thought starts, the fundamental research divorced from all thought of its ultimate use or effect, we may claim that this is one of our great assets. Complacency is always disastrous, and I do not want to be understood as asserting that there are no improvements to be made in the system of combining such fundamental research with university teaching which has grown up in Great Britain. But with all its blemishes, this system has succeeded in keeping our science, and physics in particular, well in the forefront of the world's scientific endeavour, and this success is due to the existing structure.

I think this is worth stressing because ardent reform is in the air, particularly in the direction of a more conscious planning of the fields of research and their division between different centres, and of the foundation of institutions for pure research divorced from teaching. Proposals for the latter should, I think, be scrutinized very carefully. The great asset of university research is the constant flow of young men through the university, bringing their own original and fresh minds to bear on the lines of work of the school to which they come, and of the contacts between men engaged in widely different subjects. Some few men of science remain individualists all through their careers, working alone or with one or two assistants. Examples of physicists of this type must be in all our minds, and we recognize the great contributions they have made to our science. But the majority, after the first decade of their research careers, continue to live their scientific lives for the most part through their students. Battening upon students, using their freshness for selfish ends, is of course one of the major scientific crimes, and unhappy is the laboratory which has such a head, but there is a better and more normal side to the picture. The purest pleasure in scientific work is to see the germ of an idea one has planted in a younger man's mind develop in a way and to an extent one could not have achieved or foreseen oneself, and to see him get recognition for his work. I think too that teaching, if treated as the art of putting ideas in a simple and fascinating way, is one of the great safeguards against getting stale. There are many periods when research goes badly and is disappointing, and it is refreshing to have as a background the regular teaching routine, with the satisfaction it brings of a necessary and congenial task duly accomplished.

In contrast to the flow of keen young research students through a university, a central research institution has a comparatively static staff and there is considerable danger of fossilization. As would be expected, this tendency is much more noticeable in the later stages; it is scarcely likely to appear within the first decade of an institution's existence. It is less likely to occur when the central institution has a constant flow of men through it, who are given research grants and are attracted by the special facilities for work in their chosen line, for such a place is in effect a school for postgraduate study and has the same advantages as a university. Fossilization is seen at its worst in the laboratories where there is no such flow, where members of the research staff enter as young men and continue to do work of much the same character throughout their lives, and where advancement is rather by seniority than merit.

To sum up, it is doubtful, to say the least of it, whether the advancement of pure science is fostered by taking men from universities and setting them to work in central research institutions devoted to some special branch, however fine its buildings and equipment. The necessary stimulus appears somehow to be lost. A curious fatality attends such conscious planning of research. Large endowments given to special fields are apt to produce comparatively meagre results, which are completely outdistanced by some unplanned fundamental discovery appearing at first to have little bearing on the subject. Polanyi (Manchester School of Economic and Social Studies, Oct., 1938) has put this point very well in an article on the "Rights and Duties of Science". It will be objected that a central research institution can provide equipment and other facilities on a scale which may be impossible at a university, and I think that this valid objection points the way to the right solution. The strikingly successful places of this kind are those which may be regarded not as a body of men, but as a body of equipment. Such a place has a nucleus of permanent staff and accumulates traditions of technique peculjarly its own, but its main service is as a place open to all for short periods of intense work, and its main population a changing one.

\section{Physics in Industry}

Although we have good reason to be proud of the contributions made by Great Britain to fundamental scientific knowledge, we cannot feel satisfied that full advantage is taken of this asset in our industries. The educational system has a heavy responsibility to bear. In Bernard Shaw's "Major Barbara" the millionaire Undershaft is looking for a successor to whom he can hand over the control of his great armament firm, and deplores the difficulty of finding a boy of native genius who has not been spoilt : "if he shows the least ability, he is fastened on by schoolmasters; trained to win scholarships like a racehorse ; crammed with second-hand ideas ; dulled and disciplined in docility and what they call good taste; and lamed for life so that he is fit for nothing but teaching."

The bitter truth of this reproach must have struck many who have trained successive generations of honours students at a university. In former days many boys of the right type went straight into industry, and Great Britain's leading position was 
largely due to their inventive genius. Nowadays the majority get scholarships which enable them to go on to universities, and it is our responsibility to see that we give them the right training and send them back to industry to play their part. Two difficulties stand in the way. In the first place, the boy has lost something vital through the too close attention to his studies demanded by the need to win scholarships and pay his way. We cannot sell him to the industrialist when we have finished with him; he has not learnt to mix with other people and form one of a team, to take responsibility, to trust his own judgment and have initiative. Such qualities are learnt through games, hobbies, camps, running school activities and a host of other things which most boys get but from which the really clever boy is too often largely debarred by being recognized as a potential scholarship winner. In the second place, too many of our best students want safe jobs with immediate returns. The sacrifices they and their parents have made, and the work they have put into their learning, make them feel that their high honours degree should by itself be a qualification for a good post. They regard their training as a guarantee that they shall be put in a senior position, not as a preparation which should help them to show that they deserve one. When they go into industry and come in contact with men who have not had a university training, there is irritation on both sides. The industrialist compares them unfavourably with boys who have worked their way up and become men of the world ; the university product cannot understand why the knowledge he has so painfully acquired does not entitle him to immediate recognition.

I have purposely painted the picture in the darkest colours, knowing well how many cases of success might be quoted in refutation, because $I$ wish to consider the remedies. I think the long course through grammar or secondary school and university represents too unbroken a concentration on the acquisition of knowledge. I have on three occasions had the interesting experience of being a visiting professor for several months at various American universities. Although science students in Great Britain may be more advanced on the purely academic side than American youths of corresponding age (they can answer harder examination questions), it was my impression that the American student is more practical, handy, and bold at setting up apparatus. He gets this largely through his experience in the long summer vacation, it being a general practice to engage in some form of manual work. It is not so easy to organize similar activities for our students, though a certain number already are taken on for short periods by industrial firms. I think, even when this is done, that the periods are too short and come too late. The important time to make the break, it seems to me, is between school and university. If all our honours physics students had at least six months working for an apprentice's wage in some industrial concern, before they came to the university, I believe it would be of the greatest benefit not only to those who plan an industrial career later, but also to those who will become teachers of the next generation in due course and should have seen something of a wider world.

One suggested scheme for the future is therefore to copy our engineering confrères, and encourage physics students to put in a spell at works between school and university. Another suggestion is to follow the example of the medical schools. Though a large part of the teaching in a medical school is done by the permanent staff, an important part is that given by practising physicians and surgeons in the form of short specialized courses. Why not invite some of our leading technologists to do the same in our physics schools? As well as giving the students a valuable experience, it would give the industrial experts a place in our universities, a right to take part in their counsels and help to guide their policy.

Finally, there is the possibility of bringing back senior men in industry for short or long university courses specially arranged for them. Such courses can range from a conference devoted to intensive study of some special branch lasting for a few days or a week to a refresher scientific course extending over months. There is one conclusion to which I have come, as a result of being concerned in the organization of short courses of this kind, which applies to all types. The most successful examples are those where the university has concentrated on giving the industrialists a well-prepared summary of recent advances in pure or fundamental science, not those where it has attempted to go outside its own field and talk about "Physics in Industry". Let each man stick to his own job. Advances are so rapid, the literature is so voluminous, that a busy industrialist must find it difficult to keep abreast of the times. This is where his university colleagues ought to be able to help him, if they are worth their salt. They can sort the wheat from the chaff, tell him what new ideas are important and what are not, and provide him with a background of knowledge which he can use to solve the many problems of his particular industry. The industrial physicist on his side has something to which the university physicist cannot aspire, a wide and expert knowledge of the many problems of his industry and a sense of values as to what is important to it. It is for him to see how this new knowledge may aid him.

The same consideration applies in another way to research carried out in the universities at the behest of industry, and perhaps supported by it. Such arrangements forge the links closer, which we all desire, and can have highly important results. They must fit in, however, with the main function of university research, which is to increase the body of fundamental knowledge irrespective of its immediate application. This separation of function must be kept in mind. Any knowledge discovered at a university should be free to all, and the university scientist should not be forced to keep his knowledge in watertight compartments, to remember what he may divulge and what he must regard as the peculiar property of a particular outside body which is financing a research in his laboratory. Freedom of discussion and exposure of his work to general criticism are the breath of life to the university worker.

\section{Physicists in the Service of the State}

The industrial research associations and laboratories partially or wholly supported by the nation, which have been started since the War of 1914-18, are in some respects in an intermediate position between the universities and industry. Their work is designed to help their particular industry, but they are also repositories of general knowledge and are in a position to undertake long-range research which will ultimately benefit the whole industry, as well as to apply themselves to particular problems of immediate interest.

With no disparagement of the achievements of these associations, and with full recognition that they 
represent a new experiment in organization of scientific endeavour, in planning for the future one cannot consider that the last word in defining their scope and function has been said. They have peculiar difficulties of their own. The university research worker is kept on the alert by the excitement of the chase. $\mathrm{He}$ is free to pursue any fascinating line which opens up, irrespective of its applications. $\mathrm{He}$ is hardened by the unsparing criticism of other experts if he makes mistakes of fact or logic, since his work is published and runs the gauntlet of free discussion. The industrial physicist is kept on the alert by the demands of his industry. What he is doing may affect the success or failure of a costly process, or lead to a new product for which a wide demand is anticipated. He runs the gauntlet of criticism by his colleagues in the works, and of the fierce test of results. The denger of the research association is that of its men working in a vacuum, where they miss both of these incentives.

I am emphasizing the difficulties of the research associations, not minimizing their achievements or suggesting that the experiment ought to be discontinued, a proposition to which I should be the fiercest of opponents. One ought, however, to face the existence of a widespread opinion that the flow from the research associations of Great Britain of fundamental ideas which would profoundly affect our industries has not yet reached the volume which had been hoped for and anticipated. Lip service is paid to research because it is respectable and fashionable to do so, but responsible industrialists in private express their disappointment. This is a challenge which must be met.

It seems to me that the difficulty partly arises from a wrong conception of the nature of research. To set aside a definite body of men, in a central institution, with orders to spend their whole time on research with some definite end in view, is to court disappointment. I come back to the idea of a central research association as being ideally a permanent laboratory with specialized equipment but with a changing population, not as being a permanent body of men.

While at Manchester I had an arrangement with certain firms which worked successfully. If one of their staff had a good idea, and the firm wished him to develop it without being subjected to the distractions of the works and its contacts, he was given a quiet laboratory at the University as temporary quarters. Should not the industrial research association be a place to which firms send suitable men from time to time, where equipment and assistants are available, and where they can for a year or more develop some good idea of the longer-range type? This plan has already been followed; I claim no originality for any of the ideas put forward here, but merely record those which I believe to be along the right lines. The opposite side of the picture is one which is only too commonly seen. A committee sits to direct a certain branch of research and a member proposes an investigation as worthy of attention. Staff and apparatus are set aside for it at the research association, and the men do their best to devise a technique and frame a programme. Through imperfect contact with industry, they drift off on work which may be excellent, but which is not really along lines of profound value. A committee is too impersonal a body to direct research, its members are generally too busy and important to give the necessary time and attention to detail.
When a new line of this kind is started in response to a demand by industry, it would be generally advantageous if at the same time an industrial sponsor were appointed, not necessarily a member of the committee, whose special responsibility it would be to visit the laboratory at short intervals and to spend quite a large part of his time in directing the effort. This is what in fact has happened in this War, and it is highly successful. Many extramural researches for the Services are being carried out in laboratories all over the country, and bodies like the Ministry of Supply appoint men from industry or from their own staff with precisely this function, who visit the research workers, who can be consulted freely, and who give just the required contact with what is actually needed. A day every other week of one expert's time is of infinitely more value than an hour or two of a large committee of well-known men which meets every two or three months. A similar plan widely carried out for industrial research would meet the need I have tried to express above; for the time being the sponsor drawn from industry would use the research association as his laboratory, to carry out his ideas, and there would be a constant flow of new people with new ideas through it.

\section{Research and Administration}

Some change in the methods by which Government scientific research is administered and financed appears to be very desirable. The Civil servant is, of course, right when he insists that everything should be done 'through the proper channels', and that attempts to short-circuit them lead to increased confusion and are essentially ineffective. There must be a recognized chain of authority by means of which action is taken. What we should ensure is that these channels are direct and open, not tortuous and clogged. It is here that sometimes one feels tempted to criticize the administration of research which is paid for by the Government, particularly research for the Fighting Services. An apparatus which is well designed for the administration and financial control of other classes of activity is inappropriate when it is applied to scientific research and development.

I believe the universities treat this problem in a better way. The ideal research unit is one of six to twelve scientific men and a few assistants, together with one or more first-class mechanics and a workshop in which the general run of apparatus can be constructed. I will add one further requisite : not only a good store of material but also of 'junk', old gear which has passed out of service but which pro. vides a priceless source of oddments which can be used in constructing rapidly a first rough apparatus to try out some new idea. A famous man of science of a very practical turn of mind once told me that he regarded this junk as one of the most valuable assets of his laboratory; he was at the time feeling the pinch of moving into a tidy new building in which it had not yet had time to accumulate. Few who have an inspiration for a new piece of apparatus can visualize exactly how it will work to the extent of making a blue print of it. It grows by the close personal contact between researcher and mechanic, who should work side by side. It is not wasteful to duplicate lathes and other machines by giving each group its own workshop; the time of researchers is far more expensive than the overheads on machinery. With the same object in view, that 
of allowing the researcher to try out his ideas with as little delay as possible, the decision as to what particular piece of apparatus should be bought is best left to the researcher in all but major items. $\mathrm{He}$ should have an allowance for apparatus, to be spent at his discretion. The bills are passed through a central office, but the important thing is that the researcher should be free to get what he wants while in red-hot pursuit of the idea, and not have to wait to convince a central authority that it is necessary and order through it. This makes for true economy in the long run.

It may be objected that the freedom from control advocated here would be abused if it were granted. The point to be made in answer is, I think, that the check upon expenditure should be one of general review at the end of regular periods, not one of each detail.

\section{Appointments}

The working of the Central Register has been so interesting that one would like to see a permanent body with the same function set up after the War. We train our students for three or more years at the university, devoting much time and energy to their preparation for their careers. Do we pay an adequate amount of attention to directing them into the right careers when they leave us, a matter which is in every way as important as their training ?

Students are helped to find posts in two ways, either through the head of the department in which they have worked, or through a university appointments board. Outside bodies often apply to appropriate heads of departments when they have a post to fill, and consider they may have students of the right type, and much effective placing of square pegs in square holes is done in this way. However, I have always felt, as head of a department, that too much is left to chance by relying on applications of this kind.

A university appointments board has a better opportunity to survey the whole field both of posts and men, and many such boards do excellent work. They have their own particular difficulties, however. Too often the best men are placed by heads of departments or by their own efforts, without consultation with the appointments board, and the latter is saddled with the difficult task of finding posts for the less attractive candidates. This reacts unfairly on its reputa. tion for supplying good men, and it also means that its wider knowledge of the field is of little use just where it should be most important, in the matching of the very best men with the best posts. An appointments board of the right kind should be the channel through which most appointments are normally arranged, not a last resort of the desperate.

I cannot help feeling that it would pay us handsomely to centralize the arranging of appointments of physicists after the War, much as it has been done during the War. Any central board which did this work for the whole of Great Britain would require an absolutely first-rate man at its head whom we could all trust, for he would have grave responsibilities, but the task is so important that it is a worthwhile one for such a man. I envisage the board as keeping a dossier of every physicist in the country, such as the Central Register now has in its records. The total crop of young physicists each year is two to three hundred, a comparatively small number to handle, and the total number in Great Britain is, say, ten times as great (any more precise estimate de- pends on the definition of a physicist). It should not be dificult to establish a central channel for advising men about suitable posts and helping the very best men to get the most important posts, as each year's contingent comes to be considered. I know that I, as head of a physics department, would feel much more confident that my students were taking up the right work if I had such a centre to consult. I would feel that it had a much wider knowledge of the possible careers than I could attain to by my own rather sporadic efforts, because all employing bodies would consult it when once its reputation was firmly established.

The implication of this suggestion will be realized. It is in effert a proposal to organize appointments boards by subjects rather than by universities, and would require careful planning before it could be made effective. The intimate personal knowledge of the student acquired by the department in which he has worked is fundamental to any scheme, but the War has taught us the value of having one centre for the whole country.

\section{Summary}

The foregoing appraisal of our assets and our problems may be summarized as follows. We breed the right kind of physicist, and the combination of pure research with teaching at our universities, together with the constant flow of young research students through university laboratories, is effective in producing fundamental advances in pure science of the highest quality. We are not so successful in using this asset in the field of applied physics, and some of the causes are analysed here and remedies suggested. The training of our physicists is literally too academic. This does not perhaps matter so much in the case of men taking up pure research, but it is a big handicap to the men going into industry. It is suggested that more of our physicists, now that their subject has made a recognized place for itself in industry, should have works experience as engineers do, and that the best time for the relatively shorter period they can afford to spend in works is between their school and university. An early experience of this kind would make it easier for the student to take his place in industry when he leaves the university.

We wish to ensure that the undoubted inventive genius and scientific ability of the students we train is used by industry to the best advantage. Striking successes have been achieved by industrial organizations which are large enough to have research laboratories of their own. The close contact with the works provides the inspiration and sense of practical values which are essential for fundamental and original ideas profoundly affecting the industry. Research associations represent an attempt to advance the standard of technical achievement for groups of firms, many of which cannot afford laboratories of their own. Although such associations have scored many successes, they have been successes of tactics rather than of strategy; the conditions under which they work make it difficult for them to produce the really fundamental ideas. It has often been stressed that a primary requisite for their success is that the firms which support them should be willing to pool their knowledge and consent to problems which they know to be really important being handed over to a central organization; no scheme can hope to work unless this is done. If such a pooling is carried out by general agreement, it 
would be possible to alter the character of a central research organization. At present its greatest danger is that of becoming a static body of researchers cut off from the real needs of industry. It should be able to become a common research centre with a continuous flow of men through it, providing a laboratory where any man with a good idea could come to work it out, and a source of men going back into industry with a wider knowledge of all its problems. It is only under such conditions that really fundamental advances can be made.

\section{THE EYE IN INDUSTRY}

$\mathrm{C}$ URRENT interest in the health of industrial workers and in the maintenance of a high level of output made the conference on the "Eye in Industry", held under the auspices of the London Branch of the Institute of Physics on June 20, very opportune. During the first half of the proceedings six papers were given on different aspects of the subject, followed, after tea, by a lively discussion, in which many of the audience took part. The success of the meeting was enhanced by the kindly hospitality enjoyed at the South-West Essex Technical College, where the conference was held.

In the opening paper, Dr. W. D. Wright gave three reasons for a discussion on the eye in industry as opposed to the eye in other spheres of human activity. There is in the first place the special nature of many of the tasks that have to be undertaken and that are peculiar to industry, tasks, moreover, that have to be repeated and continued for many hours at a stretch. Secondly, there is the question of responsibility, either on the part of the employer or possibly of some Government department, for the health of the workers. In the home, the individual should, so far as his means permit, make his own arrangements for good lighting and avoidance of eyestrain, but in the factory the onus rests on the employer. Any discussion should therefore aim at stirring the interest and the conscience of the employer, providing him with the data that he may properly demand and informing him of the facilities already available for the adequate solution of visual problems. There is thirdly the question of output and efficiency, matters closely related to good seeing.

Hence, although the eye responds in the factory in much the same way as it responds elsewhere, yet there are excellent reasons for paying special attention to its performance under industrial conditions. The importance of the eye, as distinct from the other sense organs, lies, of course, in the fact that a very large fraction of our knowledge of the external world is derived visually. Nearly all the information which we have of our immediate surroundings and of the events taking place in the vicinity is obtained from the very variegated pattern of light, shade and colour which is focused by the lens system of the eye on to the light-sensitive retina. Shape, size, texture, distance and movement of an object, are all observed and recorded because of the existence of contrasts between the object and its background and between different markings on its surface, as in the grain in a piece of wood, so that good seeing demands good contrast perception. Attention has to be paid to the image-forming part of the visual system, as this may be defective and require correction with spectacles, and also to the performance of the light-sensitive mosaic on the retina, which can detect small contrasts and resolve finer detail when the level of illumination is raised. Eyestrain occurs when the muscles controlling the convergence of the two eyes on to the object under examination and those governing the focusing of the lens system have to operate under conditions of poor visibility and distracting lighting. It is the job of the employer to provide conditions that achieve the best possible compromise between the requirements of his technical processes and the maintenance of maximum visual efficiency.

Mr. E. W. H. Selwyn illustrated this compromise by reference to the peculiar problems that arise in the photographic industry in connexion with the illumination of dark rooms. Sufficient light has to be provided to conduct the various photographic processes, but not so much as to fog the emulsion. In choosing the colour of the light to be used, a balance has to be struck between the parts of the spectrum to which the photographic emulsion is least sensitive and the eye most sensitive, taking into account the changing spectral sensitivity of the retina in dim illumination. It follows that the most efficient colour of the illumination will vary with the type of emulsion : orange for ordinary emulsions, red for the orthochromatic type, and green for the panchromatic and infra-red forms. In all cases the level of illumination is low, leading to poor visual acuity and contrast perception. As a consequence, objects such as dark room clocks must be large, and white markings should be provided to assist in getting about the dark room-aids reminiscent of the black-out.

Another interesting aspect of the problem is concerned with the time required to become adapted to the dark room illumination. In rooms illuminated by red light, vision, even when fully adapted, is mediated largely through the cone mechanism in the retina and the cones acquire their maximum sensitivity after only a few minutes. In the rooms illuminated by green light, on the other hand, the rods will operate, and as these take at least thirty minutes to acquire their maximum sensitivity, there is a marked difference in the adaptation times for the two forms of lighting. Mr. Selwyn also reported his experience that when working in a dark room he found that he required the aid of negative lenses with a power of -2 dioptres in order to focus distant objects clearly. This he attributed to the spherical aberration in the lens system of the eye, since at low intensities the iris is expanded and the marginal zones of the system come into action. There was some difference of opinion on this matter during the discussion, both as to magnitude of the effect and its cause. It would appear that some observers have not been conscious of the need for negative lenses; indeed, one speaker maintained that positive lenses were required, yet it is not a matter that should be lightly dismissed without further investigation.

The part played by light in aiding the performance of the eye was dealt with by Mr. W. R. Stevens. He stated the basic principles of good lighting, including adequate illumination, reasonable uniformity, freedom from glare and the provision of the proper contrast between the object and its surround. He urged the greater use of colour, both as a means of improving contrasts and in brightening our workshops ; in Great Britain we tend to be conservative in our devotion to greys and other dull colours for the decoration of machinery, with the notable exception 